\section{Estudo \\ CoDebate}

em Testão

Dlanejamento
Revista Estudo \& Debate, Lajeado, v. 26, n. 1, 2019. ISSN 1983-036X

DOI: http://dx.doi.org/10.22410/issn.1983-036X.v26ila2019.1949

\title{
PERFIL SOCIOECONÔMICO DOS POBRES: UMA ANÁLISE COM BASE NA REGIÁO NORDESTE E EM SUAS MESORREGIÓES NO PERÍODO DE 1980 A $2010^{1}$
}

\author{
Anderson Moreira Aristides dos Santos ${ }^{2}$, Vinícius Castro Moreira da Silva ${ }^{3}$
}

\begin{abstract}
Resumo: O objetivo deste artigo é analisar o perfil socioeconômico dos pobres do Nordeste e de suas mesorregiōes, utilizando os microdados do Censo no período de 1980 a 2010. Primeiramente, os pobres foram classificados pela abordagem monetária com base na linha de pobreza do Programa Bolsa Família $(\mathrm{R} \$ 140,00)$. Posteriormente, aspectos além da renda foram analisados, tendo como foco indicadores de privação dos pobres nas dimensôes: educação, infraestrutura do domicílio e posse de bens. Houve melhorias importantes ao longo do período e uma menor distância entre os indicadores de pobres e não pobres. $\mathrm{O}$ saneamento, educaçáo dos adultos e mesmo a posse de bens básicos como geladeira se encontram em um patamar de privaçáo bastante insatisfatório. Há maiores privaçóes para os pobres da área rural e existência de heterogeneidade entre as mesorregiōes. Políticas públicas precisam levar em consideraçáo que os pobres classificados monetariamente possuem diferentes condiçóes socioeconômicas de acesso a bens e serviços básicos, com precariedade, principalmente, no meio rural e em mesorregióes específicas.
\end{abstract}

Palavras-chave: pobreza, perfil dos pobres, Nordeste.

\section{SOCIOECONOMIC PROFILE OF THE POOR: AN ANALYSIS BASED IN THE NORTHEAST REGION AND ITS MESOREGIONS IN THE PERIOD OF 1980-2010}

\begin{abstract}
The objective of this paper is to analyse the socioeconomic profile of the poor of the Northeast and its mesoregions, using the Census microdata from 1980 to 2010. Firstly, the poor were classified by the monetary approach based on the poverty line of the Bolsa Família Program (\$BRL 140.00). Subsequently, aspects besides income were analysed, focusing on indicators of deprivation of the poor in the dimensions: education, home infrastructure, and ownership of assets. There were significant improvements over the period and a smaller gap between indicators of poor and non-poor. The sanitation, adult education, and even the ownership of basic
\end{abstract}

1 Agradecemos ao financiamento da Fundação de Amparo à Pesquisa do Estado de Alagoas a um projeto que gerou o presente trabalho (Edital no 13/2016- Apoio a Pesquisas- PPGs/Humanidades). Os comentários dos pareceristas anônimos foram valiosos, contudo, eventuais erros são de responsabilidade dos autores.

2 Professor no Curso de Ciências Econômicas e no Mestrado em Economia Aplicada (FEAC/UFAL).

3 Graduando no curso de Ciências Econômicas da Universidade Federal de Alagoas. 
goods such as a refrigerator are at a rather unsatisfactory level of deprivation. There are greater deprivations for the rural poor and heterogeneity among the mesoregions. Public policies need to consider that the monetarily poor have different socioeconomic conditions of access to basic goods and services, with precariousness mainly in the rural environment and in specific mesoregions.

Keywords: poverty, profile of the poor, Northeast.

Classificaçáo JEL: I32

\section{INTRODUÇÁO}

Diversos trabalhos têm observado que, principalmente na década de 2000, houve importantes ganhos sociais no Brasil, tais como reduçōes da pobreza e da desigualdade de renda (IPEA, 2013; ROCHA, 2013). Apesar disso, ainda existem grandes desafios, principalmente na região Nordeste. Como destacado em Buainain, Dedecca e Neder (2013), existe uma elevada concentração regional da pobreza, sendo que o Nordeste é a região que possui maiores proporçôes e número absoluto de pessoas vivendo com renda abaixo da linha de $\mathrm{R} \$ 140,00^{4}$.

Ademais, há diferenças significativas quando a análise é realizada de maneira mais desagregada como para mesorregióes, microrregióes e municípios. Por exemplo, Soares et al. (2016) mostram que níveis altos de pobreza são encontrados, principalmente em municípios das regióes Norte e Nordeste, em especial para os domicílios agrícolas (que possuem pelo menos uma pessoa na residência empregada nesse setor e $67 \%$ ou mais de sua renda vem dessas atividades) e rurais não agrícolas (caso em que não há indivíduos do domicílio trabalhando na atividade agrícola).

A evolução de indicadores de pobreza monetária constitui uma análise de relevância, contudo, conhecer o perfil dos pobres acaba apresentando fundamental importância, já que pode ser um diagnóstico norteador de políticas públicas, que vão além da renda. Alguns artigos, no Brasil, apresentam as características e perfis socioeconômicos dos pobres (LAVINAS; COBO, 2012; SOUZA; OSORIO, 2014). Esses trabalhos mostram que as políticas públicas têm melhorado as condiçôes de vida das pessoas mais carentes em dimensóes como educação, posse de bens, entre outras, apesar do acesso à infraestrutura ter avançado abaixo do esperado.

No presente trabalho, a abordagem monetária será utilizada para classificar os indivíduos em pobres e não pobres, em seguida, a análise terá como método uma abordagem multidimensional com foco nesse grupo dos pobres.

Dessa forma, este trabalho tem como objetivo principal analisar o perfil dos pobres com base na regiáo Nordeste e em suas mesorregióes, em uma análise relativamente longa, cobrindo o período de 1980 a 2010. Busca-se assim, mensurar e analisar índices de privação nas dimensões educação, infraestrutura do domicílio e posse de bens.

4 Não há uma linha de pobreza consensual e oficial. Para uma discussão de diferentes linhas de pobreza, ver Soares (2009). 
A despeito da importante contribuição da literatura, não encontramos trabalhos que realizassem uma análise do perfil dos pobres de maneira mais desagregada para regiáo Nordeste e nem uma análise mais longa, onde esses artigos têm analisado principalmente a década de 2000 (BUAINAIN; DEDECCA; NEDER, 2013; LAVINAS; COBO, 2012; SOUZA; OSORIO, 2014).

Este artigo está estruturado em quatro seçóes além dessa. A próxima seção busca realizar uma revisão da literatura com foco na pobreza multidimensional e das condiçóes socioeconômicas dos pobres. Na terceira seção, a base de dados, os indicadores e o método serão descritos. A seção seguinte apresentará a análise dos resultados. Por fim, na última seção, serão realizadas as consideraçôes finais.

\section{REVISÁO DE LITERATURA}

Esta revisão focará em alguns dos principais trabalhos empíricos, que analisam a pobreza multidimensional e/ou o perfil socioeconômico dos pobres (classificados pela abordagem monetária) no Brasil e na regiáo Nordeste. Entretanto, uma breve explanação sobre alguns aspectos teóricos será realizada.

A pobreza conforme a abordagem monetária pretende classificar os indivíduos em pobres e não pobres, onde eles são identificados pelas suas insuficiências de renda. Neste caso, um segundo conceito passa a ter grande importância, o da linha da pobreza, que é o limiar dessa classificação 5 .

Já na abordagem multidimensional, a análise busca aspectos além da renda. Uma abordagem de grande destaque é a proposta por Sen $(1985,2000,2001)$ que analisa a pobreza como privaçóes das capacitaçóes. Assim, os conceitos de funcionamentos (functionings) e capacitaçóes (capabilties) são importantes para o entendimento dessa abordagem. Os Funcionamentos estão relacionados a atividades ou estados de existência que o indivíduo julga importante para valorização de sua vida. Os funcionamentos incluem questóes mais gerais como o desejo de as pessoas estarem livres de doenças, como questôes mais específicas que podem estar relacionadas a diferentes sociedades, culturas e ambientes. Já a realização dos funcionamentos, como destaca Sen (2001, p. 80) "representa as várias combinaçóes de funcionamentos (estados e açôes) que uma pessoa pode realizar. A capacidade é, portanto, um conjunto de vetores de funcionamentos, refletindo a liberdade da pessoa para levar um tipo de vida ou outro.” Por fim, o conjunto de oportunidades de escolha que está à disposiçẫo do indivíduo se refere ao conjunto capacitário.

No que se refere aos trabalhos empíricos, primeiramente, referente à abordagem monetária, cabe destacar que a literatura tem observado uma queda nos indicadores de pobreza, principalmente na década de 2000 (IPEA, 2013; PERO; CRUZ, 2015; ROCHA, 2013). Em um estudo considerando o período de 2001 a 2013, Pero e Cruz (2015) indicam que a redistribuição de renda contribuiu de forma forte para redução da pobreza no período

5 Como destaca Mattos e Waquil (2008), a ideia base dessa abordagem é a classificação de pessoas que não estão obtendo determinados pontos ótimos (processo de maximização de utilidade do consumidor) devido à falta de renda, onde esses pontos ótimos podem ser vistos como as próprias linhas. 
2001-2005, contudo, perdendo força ao longo do tempo, sendo que essa queda foi superior em períodos de maior crescimento, onde esse último fator foi o grande responsável pela situação mais favorável no período total.

Kageyama e Hoffmann (2006) analisam a pobreza no Brasil, mesclando os conceitos de pobreza monetária e multidimensional para os anos de 1992 a 2004. Usando os dados obtidos, através da Pesquisa Nacional por Amostra de Domicílios (PNAD), foram definidos quatro indicadores de pobreza baseados na: renda (linha de pobreza de meio salário mínimo do ano 2005), água canalizada em pelo menos um cômodo, a existência de banheiro ou sanitário no domicílio ou na propriedade e luz elétrica no domicílio. Os resultados obtidos apontam para uma redução forte na proporçáo de pessoas em situaçáo de extrema pobreza multidimensional.

Lavinas e Cobo (2012) avaliam a evoluçáo da pobreza e o perfil socioeconômico dos pobres, indigentes e os não pobres, grupos que foram classificados com base nas linhas monetárias do Programa Bolsa Família- PBF ( $\$$ 140,00 pobreza e R \$70,00 indigência). A análise dessas autoras teve como foco a área rural do Brasil com dados das PNADs $2004 \mathrm{e}$ 2009. Os principais resultados demostram que houve evolução no acesso dos mais pobres às políticas de transferência de renda, a bens básicos como geladeira e à infraestrutura de saneamento. Apesar disso, o trabalho destaca que ainda existem privaçóes altas, principalmente, na área rural, que apresenta uma situação muito mais precária comparada à área urbana.

Buainain, Dedecca e Neder (2013) também tiveram como intuito caracterizar a evoluçáo do quadro da pobreza rural no país, com a mesma base de dados de Lavinas e Cobo (2012). Para esse caso, os autores separaram a população em vulneráveis (renda entre um e meio salário mínimo de 2009 , sendo que o SM era igual a $\mathrm{R} \$ 465,00)$, condição de pobreza (entre meio salário mínimo e a linha do $\mathrm{PBF}$ ) e extrema pobreza (menor ou igual a $\mathrm{R} \$ 140$, linha de pobreza do $\mathrm{PBF}$ ). Os autores mostram que melhorias ocorreram para os mais pobres nos seguintes indicadores: educação, redução do trabalho infantil, taxas de subocupação, energia elétrica, bens de consumo e acesso à terra. Apesar disso, os autores ressaltam a complexidade das privaçóes, principalmente, nas regióes Norte e Nordeste.

Gori (2012) buscou analisar a pobreza e o que a compóe de acordo com a qualidade de vida dos indivíduos através de suas percepçóes. Fazendo o uso da Pesquisa sobre Orçamentos Familiares (POF) dos anos 2002-2003 e 2008-2009, o autor definiu alguns indicadores para caracterizar a pobreza: quantidade e qualidade dos alimentos consumidos, trabalho, aposentadorias e pensóes, transferências e outras fontes. O autor verificou que, durante o período estudado, houve um aumento nos rendimentos de todas as classes sociais, em especial dos que se encontravam mais vulneráveis, consequentemente resultando numa redução na desigualdade e na pobreza no Brasil entre os anos de 2003 e 2009. O autor destaca que houve uma melhoria na percepçáo de qualidade de vida, fato ocorrido tanto na área urbana como na rural, apesar de níveis que transmitem ainda preocupação. Ademais, pessoas com nível análogo de renda tendem a expressar que estão mais satisfeitos quando residem na área rural. 
Neder, Buainain e Silva (2013) aplicam uma abordagem de mensuração multidimensional através da metodologia de Rasch ${ }^{6}$. Os dados têm como fonte a PNAD do ano de 2009, dentre indicadores como inserção produtiva dos domicílios, educação, trabalho infantil, acesso à terra, acesso à água, entre outros. Os resultados principais apontaram que a região onde se encontrou o maior número de domicílios com rendimentos provenientes de políticas de transferência de renda é o Nordeste, demonstrando a carência que existe nessa regiâo. No que concerne à educação, nota-se que nessa mesma regiáo muitas famílias possuem pessoas não alfabetizadas. Por fim, os autores destacam a importância do conceito multidimensional da pobreza validada pelo modelo de Rasch.

Souza e Osorio (2014) analisam o perfil dos pobres no Brasil, bem como suas mudanças no período entre 2003 e 2011, utilizando dados da PNAD. Os autores concluem que os avanços no país foram inegáveis com maior acesso dos pobres a bens e serviços. Contudo, as melhorias do acesso aos serviços de saneamento, principalmente para os mais pobres, ocorreram de forma insatisfatória, além de continuar existindo dificuldades para esse grupo no que se refere à inserção no mercado de trabalho. Outra análise do perfil dos pobres com dados da PNAD, nesse caso para as áreas rurais da região Nordeste no período 1991-2012, foi realizada por Mattos e Santos (2017), sendo que eles destacaram a evolução nas dimensôes condiçóes de habitação, educação e posse de bens, principalmente nessa última.

Caldas e Sampaio (2015) fazem uso da abordagem multidimensional da pobreza em seu artigo para o Nordeste brasileiro, tendo como fonte a PNAD 2009. O trabalho foca em três dimensões: monetária, com linhas diferentes para área urbana $(\mathrm{R} \$ 201,03$ para pobreza e $\mathrm{R} \$ 100,51$ na indigência) e rural ( $\mathrm{R} \$ 179,29$ para pobreza e $\mathrm{R} \$ 89,65$ considerando a indigência); habitação (acesso à água canalizada, banheiro e energia elétrica) e consumo (fogão, televisão e geladeira). Os autores constataram que a região Nordeste possui uma das maiores proporçóes de pessoas que não possuem acesso a bens e serviços de consumo e habitação, sendo assim, fazendo-se necessário que sejam direcionadas políticas públicas para suprir as necessidades básicas dessa população.

Bezerra, Khan e Rocha (2015) propóem em seu artigo fazer uma identificação e análise dos fatores que compóe a pobreza nos municípios cearenses. Para a realização do estudo, os autores fazem uso do Censo Demográfico para os anos de 1991, 2000 e 2010. Nos dados obtidos, estão contidos diversos indicadores, divididos em: acesso ao conhecimento, saúde, trabalho e previdência social e padrão de vida digno. Utilizando-se do Indicador de Pobreza Multidimensional (IPM), os autores constataram que a pobreza sofreu uma redução ao longo do período estudado. Através do modelo de dados em painel, o artigo analisou também os fatores associados à pobreza, sendo que foi encontrado que investimentos em educação, em saúde e em serviços de infraestrutura impactaram positivamente na redução da pobreza do estado do Ceará.

6 Esta abordagem busca a obtenção de um indicador claro e objetivo de pobreza multidimensional, através do uso de um amplo conjunto de variáveis, partindo da ideia de que o indicador ideal é uma variável latente. 
Golgher (2016) analisa a pobreza multidimensional na área urbana do Brasil com base nos dados da POF (2002/2003), utilizando como método uma análise fatorial. Este autor destaca que domicílios com mesmo nível de renda sofrem com diferentes níveis de privação em várias dimensóes.

Salvato, Matias e Barroso (2017) fazem uso da base de dados da POF (2008/2009) para os estados da região Nordeste, definindo dois indicadores multidimensionais de pobreza, sendo um deles relacionado à saúde e nutrição e o outro através da construção de um índice de bens. Empregando os modelos de dominância estocástica unidimensional e multidimensional da pobreza, os autores encontram certa homogeneidade nos estados do Nordeste, já que não há presença de dominância estrita.

Silva et al. (2017) apresentam uma análise da pobreza através de seu enfoque multidimensional no período de 2009 a 2015, tendo indicadores obtidos na PNAD, divididos nas dimensóes: alimentos e água, comunicação e informação (bens relacionados com esse aspecto), educação, condiçóes de moradia, saneamento, trabalho e demografia. A metodologia utilizada por esses autores foi a proposta por Bourguignon e Chakravarty (2003), sendo que eles apontam que ocorreu uma redução na pobreza multidimensional, passando de 22,56\% no ano de 2009 para 20,91\%, em 2015; embora ressaltem as situaçóes mais graves encontradas nas regióes Norte e Nordeste e nas áreas rurais.

Struminski e Raiher (2017) realizaram uma mensuração da pobreza através de três concepçôes: monetária, privaçôes e multidimensional. Os dados tiveram como fonte o censo demográfico do ano 2010. Os resultados apontaram para a existência de concentração espacial da pobreza nas regióes Norte e Nordeste do país.

Serra, Yalonetzky e Belik (2017) apresentam em seu artigo medidas de pobreza multidimensional para o Brasil nos anos 2000 e 2010, com base nos microdados dos censos do IBGE. As variáveis utilizadas se dividem em duas dimensóes: padrão de vida (água canalizada, banheiro, coleta de lixo, energia elétrica, bens de consumo duráveis e densidade por dormitório) e escolaridade (taxa de matrícula e adequação idade-série/nível de instrução). Os autores aplicam o método de Alkire-Foster auxiliado pelo modelo hierárquico proposto por Permanyer e encontram que houve queda na pobreza multidimensional apesar da existência de diferenças claras entre as áreas rurais e urbanas e uma concentração espacial nas regióes Norte e Nordeste.

\section{METODOLOGIA}

A base de dados que será utilizada nesse trabalho tem como fonte os microdados do Censo Demográfico dos anos 1980, 1991, 2000 e 2010. Contudo, destaca-se uma dificuldade devido à incompatibilidade ou ausência de variáveis para o período total, tais como: posse de fogão, tipo de parede no domicílio, variáveis gerais de mercado de trabalho, entre outras. Para extração e uniformização das variáveis, este trabalho empregou o pacote do Data zoom ${ }^{7}$ para $o$ software Stata 15.

7 Para mais detalhes ver http://www.econ.puc-rio.br/datazoom/censoArq.html. 
A pobreza é tida como complexa e multidimensional (SEN, 2000). Entretanto, inicialmente, utiliza-se a abordagem monetária para uma breve análise da evolução dos indicadores, tendo como base a linha de pobreza de R \$ 140,00 (relativa ao Programa Bolsa Família no último ano de análise), em unidades monetárias do ano de 2010 (utilizando o deflator do Censo). Dessa forma, este trabalho irá avaliar e mensurar três dos principais indicadores de pobreza monetária: proporção de indivíduos que vivem abaixo da linha de pobreza (P0), o hiato da pobreza (P1) e o hiato médio quadrático (P2). Os autores Foster, Green e Thorbecke (1984) mostram que os índices de pobreza podem ser mensurados através da seguinte fórmula:

$$
P(\alpha)=\frac{1}{n} \sum_{i=1}^{q}\left(\frac{z-y_{i}}{z}\right)^{\alpha} \text { para } \alpha \geq 0
$$

onde:

$\mathrm{z}=$ linha de pobreza; $\mathrm{n}=$ número de pessoas no total; $\mathrm{q}=$ número de pobres (dada a linha de pobreza $\mathrm{z}$ ); $\mathrm{y}_{\mathrm{i}}=$ renda e $\alpha=$ parâmetro Foster, Greer e Thorbecke (1984) $)^{8}$.

Sendo que quando $\alpha=0$, obtém-se o indicador proporção de pobres (P0), com $\alpha=1$ o indicador hiato médio da pobreza (P1), e, por fim, com $\alpha=2$ o hiato médio quadrático da pobreza (P2). As medidas FGT com $\alpha>0$ satisfazem o axioma da monotonicidade, enquanto as medidas com $\alpha>1$ satisfazem o axioma da transferência9?

Posteriormente, uma análise do perfil socioeconômico e demográfico dos pobres com base na linha de pobreza monetária de $\mathrm{R} \$ 140,00$, (por simplicidade de expressão, doravante indicados como pobres) será realizada com base nas seguintes dimensóes: educação (taxa de matrícula, ensino fundamental e taxa de analfabetismo); posse de bens (televisão, telefone e geladeira); infraestrutura da habitação (energia, sanitário, esgoto, água e densidade). De forma adicional, algumas estatísticas serão exploradas com base nos indicadores de taxa de urbanizaçáo, cor (proporçáo de negros ou pardos) e número médio de pessoas no domicílio. Assim, este trabalho irá mensurar índices de privação para cada dimensão (educaçấo, infraestrutura do domicílio e posse de bens). Destaca-se que, naturalmente, a disponibilidade de indicadores reflete em limitação da análise. Todas as variáveis estão descritas no Quadro 1.

8 Para uma importante e rica leitura acerca de indicadores de pobreza e desigualdade de renda, ver Hoffmann (1998).

9 O axioma da monotonicidade indica que, considerando outros fatores constantes, uma redução na renda dos mais pobres deveria aumentar a pobreza; enquanto o axioma da transferência defende que (novamente com outras situaçóes e fatores constantes) uma transferência de renda de uma pessoa mais pobre para uma outra mais rica deveria aumentar a pobreza. 
Quadro 1- Detalhamento das variáveis do artigo

\begin{tabular}{|c|c|c|}
\hline Dimensão & Variável & Descrição \\
\hline \multirow{3}{*}{ Educaçáo } & Tx. Matrícula & $\begin{array}{c}\text { Percentual de crianças pobres de } 7 \text { a } 14 \text { anos que não } \\
\text { estavam matriculadas na escola }\end{array}$ \\
\hline & Ens. Fundamental & $\begin{array}{l}\text { Percentual de indivíduos pobres de } 15 \text { anos ou mais que } \\
\text { náo possuíam pelo menos o ensino fundamental }\end{array}$ \\
\hline & Tx. Analfabetismo & Percentual de pobres de 15 anos ou mais analfabetos \\
\hline \multirow{5}{*}{$\begin{array}{l}\text { Infraestrutura } \\
\text { da Habitaçáo }\end{array}$} & Energia & $\begin{array}{c}\text { Percentual de indivíduos pobres que não possuíam energia } \\
\text { elétrica }\end{array}$ \\
\hline & Sanitário & $\begin{array}{l}\text { Percentual de indivíduos pobres que não possuíam } \\
\text { sanitário }\end{array}$ \\
\hline & Esgoto & $\begin{array}{l}\text { Percentual de indivíduos pobres que não possuíam } \\
\text { sanitário com esgoto ligado à rede geral ou fossa séptica }\end{array}$ \\
\hline & Água & $\begin{array}{c}\text { Percentual de indivíduos pobres que não possuíam } \\
\text { canalizaçáo interna ligada à rede geral ou poço ou } \\
\text { nascente }\end{array}$ \\
\hline & Densidade & $\begin{array}{c}\text { Percentual de indivíduos pobres que residiam em } \\
\text { domicílios com densidade por dormitório de mais do que } \\
\text { duas pessoas }\end{array}$ \\
\hline \multirow{3}{*}{ Posse de Bens } & Televisão & $\begin{array}{c}\text { Percentual de indivíduos pobres que não possuíam } \\
\text { televisáo no domicílio }\end{array}$ \\
\hline & Telefone & $\begin{array}{l}\text { Percentual de indivíduos pobres que residiam em } \\
\text { domicílios em que nenhum morador possuía telefone }\end{array}$ \\
\hline & Geladeira & $\begin{array}{c}\text { Percentual de indivíduos pobres que não possuíam } \\
\text { geladeira no domicílio }\end{array}$ \\
\hline \multirow{3}{*}{$\begin{array}{l}\text { Índices de } \\
\text { Privaçáo }\end{array}$} & I. Educação & $\begin{array}{c}\text { Média dos indicadores da dimensão dividida por } 100 \\
\text { (escala de } 0 \text { a } 1)\end{array}$ \\
\hline & I. Infra. Habitação & $\begin{array}{l}\text { Média dos indicadores da dimensão dividida por } 100 \\
\text { (escala de } 0 \text { a } 1 \text { ) }\end{array}$ \\
\hline & I. Posse de Bens & $\begin{array}{c}\text { Média dos indicadores da dimensão dividida por } 100 \\
\text { (escala de } 0 \text { a } 1)\end{array}$ \\
\hline
\end{tabular}

Fonte: Elaboração dos autores.

Notas: Para o ano 2000, a informação da variável geladeira corresponde a posse de geladeira ou freezer, devido ao censo não desmembrar esses bens. A informaçáo de telefone em 2010 se refere especificamente a celular.

Necessita-se de uma normalização em torno de valores mínimo e máximo para cada variável, além de pesos para composição do índice, como realizado comumente em outros, tais como no Índice de Desenvolvimento Humano (IDH) e no Índice de Vulnerabilidade Social (IVS) ${ }^{10}$.

Primeiramente, optou-se por utilizar pesos iguais para as variáveis e dimensóes, como no IVS. Costa e Marguti (2015) defende que essa estratégia, mais do que o uso de métodos

10 Para mais detalhes do IDH ver http://www.atlasbrasil.org.br/2013/pt/o_atlas/idhm/ e do IVS, http://ivs. ipea.gov.br/index.php/pt/. 
estatísticos para definição de pesos, leva em conta a questão da diversidade presente nos diferentes contextos de realidade de regióes desagregadas e mudanças ao longo tempo, que pode tornar questionável e apresentar grande dificuldade na adoção de modelos para tal finalidade. Deixa-se claro que essa estratégia pressupóe condiçóes equivalentes nas diferentes vulnerabilidades.

Já em relação aos mínimos e máximos, utilizar-se-á os valores zero e um. Algumas das razóes para essa escolha são: i) todas as variáveis possuem proporçóes bastante altas no início do período de análise, principalmente nas dimensóes condiçóes de infraestrutura e posse de bens; ii) quando a análise é pensada em termos individuais, o valor de realização é zero e de privação um, sendo que em dimensões que levam em consideração a população total (infraestrutura do domicílio e posse de bens), o índice pode ser interpretado como a média das privações individuais médias (baseadas nas variáveis que compóem a dimensão); iii) como os indicadores são proporções, o índice de privação acaba possuindo simplicidade, já que está relacionado às variáveis originais do modelo; iv) resultados com base em outros métodos de estabelecimento desses limiares, por exemplo, na metodologia do IVS ${ }^{11}$, possuem conclusóes qualitativas semelhantes, e nos casos das dimensóes infraestrutura e posse de bens, quantitativamente próximos; iv) alguns índices, como a dimensão educação do IDH, também utilizam esses valores.

Dessa forma, com pesos iguais e limiares da normalização assumindo os valores zero e um, o índice de privação da dimensão correspondente é mensurado pela média aritmética das variáveis, dividido por cem para obter uma escala variando de zero a um. Um índice mais alto indica maior privação na dimensão. Cabe advertir que, no presente artigo, o termo "privação" está sendo utilizado como sinônimo de não possuir o bem ou serviço em questão, já que não há informaçóes de desejo das pessoas. Por exemplo, o indivíduo pode ter escolhido não ter uma televisão, mais do que esse fato ser uma privação. Contudo, considerando o público alvo, pobres monetários, e que todas as variáveis são bens e serviços básicos, das quais geralmente as pessoas precisam e/ou desejam ter com base em informação, alimentação entre outros aspectos, acredita-se que a diferença entre privação e não posse não seja significativa.

Todos os resultados serão explorados para a região Nordeste, primeiramente de forma agregada, com o objetivo de mostrar a complexidade da pobreza comparando área rural e urbana, pobres e não pobres e os não pobres do Nordeste com os pobres do Sudeste. Posteriormente, serão analisados resultados das mesorregióes em percentis dos diferentes indicadores, utilizando também mapas com intuito de observar uma visualização sintética.

Por fim, iremos buscar, brevemente, estabelecer padróes locais de autocorrelação espacial, considerando todas as mesorregióes do Brasil, utilizando a abordagem de um Local Indicator of Spatial Association - LISA (ANSELIN, 1995). Para tanto será utilizada a matriz geográfica de contiguidade por convenção rainha (Queen). Essa abordagem visa

11 Utilizou-se a proposta de limiares do IVS, tendo zero como mínimo, e a média mais duas vezes o desvio padrão do período, como máximo. Esses e quaisquer resultados que forem comentados, mas não apresentados no presente artigo, estão disponíveis conforme contato aos autores. 
encontrar se o perfil dos pobres tem alguma correlação em termos espaciais, em outras palavras, se, por exemplo, o fato de uma mesorregião possuir índices socioeconômicos ruins da populaçấo carente tem alguma correlação com a existência de indicadores precários das mesorregiôes vizinhas. Esta informação pode dar algum subsídio para um melhor foco de políticas públicas.

\section{ANÁLISE DOS RESULTADOS}

A Tabela 1 contém a evoluçáo dos indicadores de pobreza monetária (P0, P1 e P2), baseada nos percentis das situaçōes presenciadas nas 42 mesorregióes do Nordeste ${ }^{12}$. Por exemplo, o valor máximo da proporção de pobres caiu de $83 \%$ para $51 \%$. Em 2010, as cinco piores mesorregiôes com maiores índices P0 eram: Sertão Alagoano, Leste Maranhense, Centro Maranhense, Noroeste Cearense e Sertóes Cearenses. Enquanto as cinco menores proporçóes de pobres (P0) estavam em: Metropolitana de Fortaleza, Metropolitana de Salvador, Metropolitana de Recife, Leste Potiguar e Mata Paraibana.

Tabela 1- Indicadores de pobreza monetária, P0, P1 e P2, distribuição em percentis das 42 mesorregióes do Nordeste, 1980-2010

\begin{tabular}{lcccccccc}
\hline Indicadores & Ano & Mínimo & $\mathbf{p 1 0}$ & $\mathbf{p 2 5}$ & $\mathbf{p 5 0}$ & $\mathbf{p 7 5}$ & $\mathbf{p 9 0}$ & Máximo \\
\hline \multirow{3}{*}{$\mathbf{P 0}$} & $\mathbf{1 9 8 0}$ & 0,313 & 0,468 & 0,587 & 0,699 & 0,766 & 0,795 & 0,826 \\
& $\mathbf{1 9 9 1}$ & 0,411 & 0,532 & 0,654 & 0,733 & 0,786 & 0,796 & 0,82 \\
& $\mathbf{2 0 0 0}$ & 0,329 & 0,403 & 0,527 & 0,589 & 0,641 & 0,677 & 0,738 \\
& $\mathbf{2 0 1 0}$ & 0,181 & 0,241 & 0,307 & 0,356 & 0,416 & 0,446 & 0,513 \\
$\mathbf{P 1}$ & $\mathbf{1 9 8 0}$ & 0,125 & 0,208 & 0,282 & 0,372 & 0,443 & 0,496 & 0,528 \\
& $\mathbf{1 9 9 1}$ & 0,195 & 0,257 & 0,344 & 0,403 & 0,455 & 0,476 & 0,503 \\
& $\mathbf{2 0 0 0}$ & 0,16 & 0,2 & 0,285 & 0,326 & 0,381 & 0,405 & 0,491 \\
& $\mathbf{2 0 1 0}$ & 0,0882 & 0,124 & 0,152 & 0,188 & 0,23 & 0,247 & 0,302 \\
$\mathbf{P 2}$ & $\mathbf{1 9 8 0}$ & 0,0683 & 0,12 & 0,179 & 0,244 & 0,327 & 0,369 & 0,415 \\
& $\mathbf{1 9 9 1}$ & 0,115 & 0,156 & 0,22 & 0,263 & 0,309 & 0,33 & 0,353 \\
& $\mathbf{2 0 0 0}$ & 0,107 & 0,133 & 0,196 & 0,231 & 0,282 & 0,302 & 0,386 \\
& $\mathbf{2 0 1 0}$ & 0,0656 & 0,0908 & 0,107 & 0,134 & 0,165 & 0,181 & 0,223 \\
\hline
\end{tabular}

Fonte: Elaboração dos autores com base nos microdados do Censo e auxílio do software Stata 15.

Notas: $\mathrm{O}$ termo 10 indica o $10^{\circ}$ percentil, raciocínio similar para os demais casos.

A Tabela 2 apresenta as variáveis socioeconômicos dos pobres e não pobres para a regiāo Nordeste de forma agregada, no período 1980-2010. A proporçáo de negros e pardos entre os pobres é maior, assim como a taxa de urbanização é menor comparativamente aos não pobres. Apesar disso, nos dois grupos há um crescimento expressivo na taxa de urbanização ao longo do período 1980-2000, mas com números estáveis na última década. O tamanho médio dos domicílios diminuiu nesse período de análise, bem como a diferença

12 Para uma lista das mesorregióes existentes do Nordeste, ver http://www.ngb.ibge.gov.br/?pagina=meso. 
entre pobres e não pobres, fato que, possivelmente, pode ser explicado em boa parte por quedas nas taxas de fecundidade (Souza e Osorio, 2014), e também por melhorias socioeconômicas. No que se refere aos índices de privação, como o esperado, podemos observar que os pobres possuem uma situação socioeconômica pior, principalmente para os indicadores de infraestrutura da habitação.

Porém, ainda em relação aos números da Tabela 2, cabe observar as melhorias que ocorreram para a população pobre e não pobre, com ênfase para esse primeiro caso. Em relação à educaçáo, houve avanços significativos na taxa de matrícula das crianças pobres de 7 a 14 anos, queda, no período total, de 57,7 pontos percentuais na proporção de privação desse indicador; observando-se uma equalização entre esses dois grupos com números próximos a uma universalização. Essa queda ocorreu em todas as décadas analisadas, com uma maior expressividade entre 1991 e 2000. As proporçóes de pessoas de 15 anos ou mais sem ensino fundamental e a de analfabetos sofreram reduçóes significativas, porém existindo diferenças expressivas entre pobres e não pobres, e números elevados para ambos os grupos. Por exemplo, em 2010, 71,9\% dos indivíduos pobres de 15 anos ou mais não possuíam ensino fundamental.

Tabela 2- Indicadores Socioeconômicos dos pobres e não pobres do Nordeste, 1980-2010

\begin{tabular}{lcccccccc}
\hline & \multicolumn{3}{c}{ Pobres } & \multicolumn{5}{c}{ Não Pobres } \\
\cline { 2 - 8 } Variáveis\Ano & $\mathbf{1 9 8 0}$ & $\mathbf{1 9 9 1}$ & $\mathbf{2 0 0 0}$ & $\mathbf{2 0 1 0}$ & $\mathbf{1 9 8 0}$ & $\mathbf{1 9 9 1}$ & $\mathbf{2 0 0 0}$ & $\mathbf{2 0 1 0}$ \\
\hline Negros ou Pardos (\%) & 76,1 & 77,8 & 72,4 & 75,2 & 68,3 & 64,8 & 60,2 & 66,9 \\
Tx urbanizaçáo (\%) & 36,6 & 49,9 & 55,6 & 55,7 & 70,6 & 82,4 & 83,9 & 81,5 \\
No Pessoas Dom. & 7,5 & 6,4 & 6,0 & 5,2 & 5,9 & 5,0 & 4,5 & 4,1 \\
Renda (R\$ 2010) & 67,3 & 63,9 & 62,3 & 65,3 & 663,0 & 509,6 & 564,3 & 644,7 \\
Tx. Matrícula (\%) & 61,6 & 39,9 & 10,3 & 3,9 & 35,7 & 14,4 & 4,13 & 2,73 \\
Ens. Fundamental (\%) & 96,7 & 92,3 & 87,8 & 71,9 & 78,7 & 62,3 & 57,6 & 47,8 \\
Tx. Analfabetismo (\%) & 57,9 & 47,7 & 33,3 & 25,3 & 32,8 & 20,2 & 17,7 & 16,1 \\
Energia (\%) & 71,6 & 39,9 & 20,9 & 4,5 & 32,4 & 9,39 & 5,25 & 1,16 \\
Sanitário (\%) & 66,5 & 50,8 & 37,5 & 17,2 & 30,2 & 13,6 & 9,57 & 3,98 \\
Esgoto (\%) & 91,7 & 87,6 & 78,1 & 72,4 & 65,6 & 56,3 & 47,4 & 49 \\
Água (\%) & 86,6 & 71,5 & 61,5 & 43,3 & 53,3 & 27,4 & 22,9 & 17,9 \\
Densidade (\%) & 74,3 & 69,1 & 63,1 & 51,0 & 50,6 & 37,1 & 27,8 & 22,7 \\
Televisáo (\%) & 85,2 & 45,8 & 33,7 & 11,4 & 47,7 & 15,6 & 11 & 4,22 \\
Telefone (\%) & 99,2 & 98,9 & 95,0 & 38,6 & 88,7 & 76,5 & 61,4 & 13,8 \\
Geladeira (\%) & 88,5 & 58,1 & 55,6 & 24,6 & 52,4 & 18,8 & 16,9 & 6,97 \\
I. Educaçáyo & 0,72 & 0,60 & 0,44 & 0,34 & 0,49 & 0,32 & 0,27 & 0,22 \\
I. Infra. Habitaçáy & 0,78 & 0,64 & 0,52 & 0,38 & 0,46 & 0,29 & 0,23 & 0,19 \\
I. Posse de Bens & 0,91 & 0,68 & 0,61 & 0,25 & 0,63 & 0,37 & 0,30 & 0,08 \\
\hline
\end{tabular}

Fonte: Elaboração dos autores com base nos microdados do Censo e auxílio do software Stata 15.

Notas: Variáveis a partir da tx. matrícula refletem privação, por exemplo, não estar matriculado. 
Resultados de melhorias educacionais para os grupos mais pobres têm sido destacados na literatura, tal como em Souza e Osorio (2014) com dados do Brasil nas PNADs de 2003 e 2011. Já Menezes Filho e Kirschbaum (2015), com dados decenais de 1960-2010, indicam um aumento da escolaridade da população brasileira, explicado por fatores como: transição demográfica, descentralização de recursos educacionais advinda da Constituição de 1988, o Fundo de Manutenção e Desenvolvimento da Educação Básica e de Valorização dos Profissionais da Educação (Fundeb - início em 1998 com o antigo Fundef), programas de transferência de renda desde o Bolsa Escola até o Bolsa Família e programas de progressão continuada que foram implantados nos anos 1990.

As variáveis de infraestrutura também tiveram ganhos significativos. Em todas as décadas ocorreram reduçóes nas privações do serviço de energia elétrica para os pobres, sendo que a maior variação em termos absolutos foi observada ao longo da década de 1980, enquanto em 2010, nota-se uma quase universalização; no período total 1980-2010, houve uma redução de 67,1 pontos percentuais na proporção de indivíduos pobres sem esse serviço (Tabela 2). As melhorias dessa dimensão também foram verificadas nos indicadores: sanitário, água e densidade por dormitório com quedas mais fortes das privaçóes na década de 2000. Observa-se uma redução da privação para a variável esgoto ao longo do período, mas nesse caso, a variação em termos absolutos foi de menor magnitude, comparativamente aos demais indicadores dessa dimensão. A despeito dessas melhorias, as privaçóes ainda são altas. Souza e Osorio (2014) indicam que ocorreram melhorias socioeconômicas para os pobres do Brasil, porém, a questão do acesso adequado ao saneamento está longe de se encontrar em um patamar satisfatório, fato presenciado para a população geral, mas, principalmente para os mais pobres.

Já para as variáveis de posse de bens básicos, as melhorias aconteceram, principalmente, na última década (2000-2010), relacionadas a uma melhor infraestrutura do país e popularização da tecnologia da telefonia celular, já as possíveis explicações para uma menor privação da geladeira e televisão envolvem fatores como crédito, programas de transferências de renda, tal como Bolsa Família, e menor preço real dos bens. Entretanto, cabe destacar que em 2010, 24,6\% dos pobres no Nordeste ainda não possuíam geladeira.

O gráfico 1 apresenta a evolução temporal nos indicadores de privação entre pobres da região Sudeste e não pobres do Nordeste. O intuito desse gráfico é mostrar a complexidade da pobreza na região Nordeste, já que podemos notar índices próximos entre esses dois grupos. No caso da educação, esse resultado é influenciado pelas altas taxas de analfabetismo e proporção de pessoas sem o grau de ensino fundamental, principalmente entre as pessoas mais velhas. Como observado em Buainain, Dedecca e Neder (2013), o grupo de não pobres é influenciado por pessoas mais velhas que obtêm aposentadoria e passam a não estar mais com renda abaixo da linha de pobreza, apesar da baixa escolaridade. Sendo que esses autores encontram que para os grupos de pobres, extremo pobres e vulneráveis, a taxa de analfabetismo nas áreas rurais das regióes Norte e Nordeste é muito mais elevada do que nas demais regiôes. Já a infraestrutura de habitação dos não pobres do Nordeste possui o mesmo índice de privação dos pobres da região Sudeste, influenciada pela péssima cobertura de saneamento dessa primeira região. 
Gráfico 1- Índices de Privação por dimensão para os pobres do Sudeste e não pobres do Nordeste, 1980-2010

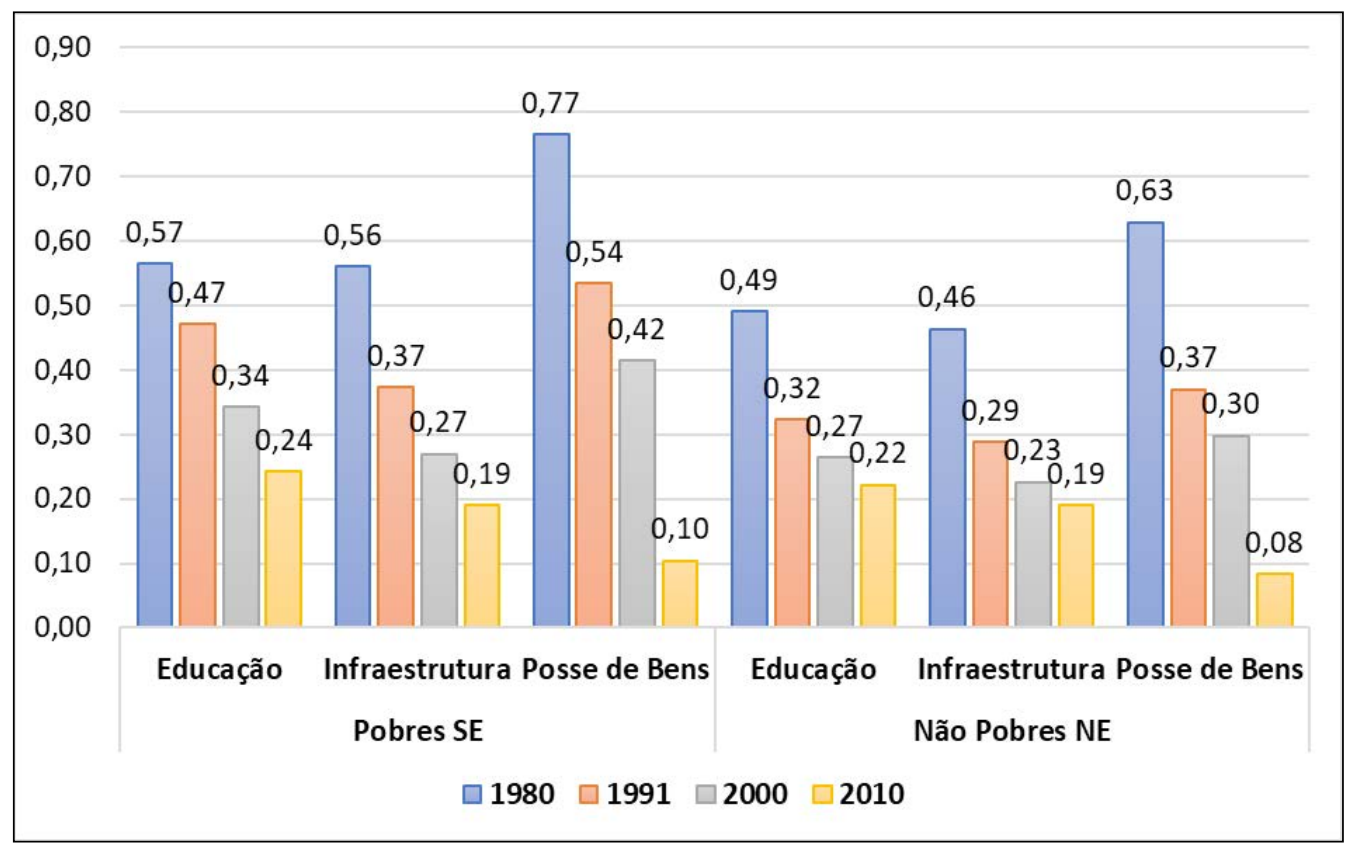

Fonte: Elaboração dos autores com base nos microdados do Censo.

As desigualdades regionais em infraestrutura são destacadas no trabalho de Arretche (2015), utilizando dados dos Censos de 1970 a 2010. A autora destaca que, entre 1970 e 1980, houve um avanço importante na infraestrutura (água, esgoto e energia) nas regióes Sul e Sudeste, beneficiado por açóes como: Plano Nacional de Saneamento (Planasa), criação da Eletrosul, Eletronorte e Itaipu. E ainda, a década de 80, conhecida como a "década perdida" em assuntos econômicos, foi marcada por expansão em serviços de infraestrutura, contudo, novamente com maior foco nessas duas regiōes. Entre 1991 e 2000, houve um avanço importante em todas as regióes do país, contudo, Centro-Oeste e Sul foram as mais beneficiadas, indicando novamente desigualdade contra as regióes Norte e Nordeste. Por fim, a última década de análise foi caracterizada por avanços importantes nessas duas últimas regiôes, principalmente para energia elétrica, serviço que foi praticamente universalizado.

A Tabela 3 apresenta indicadores dos pobres das áreas rurais e urbanas, buscando estabelecer um comparativo das diferentes privaçóes dessas regióes no Nordeste. A diferença nos valores da variável crianças de 7 a 14 anos não matriculadas, entre os pobres dessas duas áreas, praticamente desapareceu, indicando uma forte queda nessa privação com ênfase na área rural. As melhorias são observadas também nas outras variáveis, porém, as taxas de analfabetismo e proporção de pobres sem ensino fundamental são maiores na área rural. 
Tabela 3- Indicadores Socioeconômicos dos pobres das áreas rurais e urbanas do Nordeste, $1980-2010$

\begin{tabular}{lcccccccc}
\hline & \multicolumn{3}{c}{ Pobres- Urbano } & \multicolumn{5}{c}{ Pobres- Rural } \\
\cline { 2 - 9 } Variáveis\Ano & $\mathbf{1 9 8 0}$ & $\mathbf{1 9 9 1}$ & $\mathbf{2 0 0 0}$ & $\mathbf{2 0 1 0}$ & $\mathbf{1 9 8 0}$ & $\mathbf{1 9 9 1}$ & $\mathbf{2 0 0 0}$ & $\mathbf{2 0 1 0}$ \\
\hline Negros ou Pardos (\%) & 76,9 & 77,5 & 72,7 & 77,1 & 75,9 & 78,1 & 72,3 & 79,2 \\
No Pessoas Dom. & 7,4 & 6,3 & 5,9 & 5,2 & 7,2 & 6,8 & 6,5 & 5,5 \\
Renda (R\$ 2010) & 77,1 & 70,4 & 68,5 & 70,5 & 62,3 & 55,1 & 52,2 & 58,5 \\
Tx. Matrícula (\%) & 40,7 & 27,4 & 8,5 & 3,6 & 74,0 & 52,1 & 12,2 & 3,8 \\
Ens. Fundamental (\%) & 92,9 & 88,1 & 83,5 & 68,6 & 99,1 & 97,4 & 94,5 & 79,2 \\
Tx. Analfabetismo (\%) & 45,3 & 38,4 & 28,3 & 22,8 & 66,3 & 58,4 & 41,2 & 31,2 \\
Energia (\%) & 34,9 & 9,9 & 3,8 & 1,3 & 93,2 & 72,0 & 43,4 & 9,4 \\
Sanitário (\%) & 33,6 & 25,5 & 16,9 & 5,0 & 85,7 & 78,2 & 65,8 & 34,3 \\
Esgoto (\%) & 80,9 & 78,7 & 66,0 & 62,2 & 98,0 & 97,9 & 96,2 & 91,9 \\
Água (\%) & 68,3 & 49,7 & 41,1 & 21,9 & 97,3 & 95,0 & 89,5 & 72,5 \\
Densidade (\%) & 74,7 & 67,6 & 63,0 & 50,5 & 72,7 & 72,5 & 65,5 & 51,5 \\
Televisáyo (\%) & 66,2 & 42,8 & 18,6 & 6,5 & 96,5 & 60,5 & 54,5 & 18,8 \\
Telefone (\%) & 98,2 & 98,0 & 92,5 & 29,9 & 99,8 & 99,8 & 99,5 & 53,9 \\
Geladeira (\%) & 74,2 & 55,8 & 42,2 & 19,6 & 97,1 & 71,5 & 75,5 & 33,4 \\
I. Educaçáyo & 0,60 & 0,51 & 0,40 & 0,32 & 0,80 & 0,69 & 0,49 & 0,38 \\
I. Infra. Habitaçáno & 0,58 & 0,46 & 0,38 & 0,28 & 0,89 & 0,83 & 0,72 & 0,52 \\
I. Posse de Bens & 0,80 & 0,66 & 0,51 & 0,19 & 0,98 & 0,77 & 0,77 & 0,35 \\
\hline
\end{tabular}

Fonte: Elaboração dos autores com base nos microdados do Censo e auxílio do software Stata 15.

Notas: Variáveis a partir da tx. matrícula refletem privação, por exemplo, não estar matriculado.

Ainda relativo a Tabela 3, os dados de infraestrutura do domicílio mostram que o acesso à energia elétrica, na área urbana, já era praticamente universalizado no ano 2000; sendo que os ganhos de 1980-2000 ocorreram devido à melhoria de infraestrutura dessas áreas. $\mathrm{Na}$ área rural, apesar do avanço que adveio nas três décadas de análise, o principal ganho nesse indicador aconteceu na década de 2000, uma redução de 34 pontos percentuais na proporção de pobres sem esse serviço, em que o programa Luz para todos pode ter influenciado de forma positiva. Essa última década também foi marcada por quedas na privação de sanitário, esgoto, água e densidade, contudo, a variação em termos absolutos só foi maior na área rural para essa primeira variável. E ainda, em geral, os pobres da área rural sofrem maiores privaçóes; sendo que em 2010 seu índice de privação em infraestrutura do domicílio ainda era quase 2 vezes maior do que na área urbana. Fato semelhante ocorre para o índice de privação da posse de bens, com diferença, aproximadamente, de mesma magnitude.

Em resumo, há uma distância significativa entre os indicadores dos pobres das áreas rurais e urbanas da regiấo Nordeste, com maior privação para esse primeiro caso, principalmente nas dimensôes de infraestrutura do domicílio e na posse de bens; para educação essa diferença existe, mas de menor magnitude. Apesar disso, para as variáveis 
taxa de matrícula, taxa de analfabetismo, energia, televisão e geladeira, a evolução temporal implicou em uma menor diferença absoluta nos índices dos pobres dessas duas áreas. Carências maiores das áreas rurais são evidenciadas na literatura com base em dados da década de 2000 (CALDAS; SAMPAIO, 2015; LAVINAS; COBO, 2012; SERRA; YALONETZKY; BELIK, 2017; SILVA et al., 2017). Por exemplo, Lavinas e Cobo (2012), utilizando as PNADs 2004 e 2009, mostram que, nesse último ano, 95,1\% dos domicílios pobres da área urbana do Brasil tinham banheiro, sendo que esse número para área rural era de apenas 67,3\%. Esses autores também demonstram diferenças entre essas duas áreas nos serviços de água e esgoto e nos bens de consumo como geladeira, televisão e máquina de lavar.

A Tabela 4 inicia a discussão das condições socioeconômicas dos pobres, considerando as mesorregióes do Nordeste $^{13}$. Para tanto, ela contém a evolução dos indicadores da dimensão educação, baseada nos percentis da distribuição das situações presenciadas nas 42 mesorregióes do Nordeste. Alinhadas aos resultados encontrados anteriormente, as reduçóes das privaçóes ocorrem para todos os casos com ênfase na taxa de matrícula das crianças. Porém, a distância entre os indicadores dos pobres dessas áreas, principalmente para o ensino fundamental e taxa de analfabetismo, é significativa. Em 2010, a maior taxa de analfabetismo entre os pobres era de 35,6\% (Agreste Alagoano), sendo 11,9\% a menor taxa (Metropolitana de Salvador). Nesse mesmo ano, as cinco mesorregióes que apresentavam os níveis mais altos nessa variável eram: Agreste Alagoano, Sertão Alagoano, Sertão Sergipano, Norte Piauiense e Leste Maranhense. Já Metropolitana de Salvador, Metropolitana de Recife, Metropolitana de Fortaleza, Norte Maranhense e Sul Maranhense possuíam as cinco menores taxas.

Tabela 4- Indicadores de privação na educação dos pobres, distribuição em percentis com base nas 42 mesorregióes do Nordeste, 1980-2010

\begin{tabular}{lcccccccc}
\hline Indicadores & Ano & Mínimo & $\mathbf{p 1 0}$ & $\mathbf{p 2 5}$ & $\mathbf{p 5 0}$ & $\mathbf{p 7 5}$ & $\mathbf{p 9 0}$ & Máximo \\
\hline & $\mathbf{1 9 8 0}$ & 32,8 & 50,4 & 58,3 & 62,7 & 69,3 & 71,6 & 75,0 \\
Tx. Matrícula (\%) & $\mathbf{1 9 9 1}$ & 22,0 & 29,6 & 34,4 & 40,8 & 46,7 & 49,3 & 52,7 \\
& $\mathbf{2 0 0 0}$ & 6,0 & 6,9 & 8,1 & 9,6 & 12,0 & 13,9 & 17,2 \\
& $\mathbf{2 0 1 0}$ & 2,5 & 2,6 & 2,8 & 3,3 & 4,7 & 5,1 & 6,8 \\
& $\mathbf{1 9 8 0}$ & 91,3 & 94,9 & 96,5 & 97,5 & 98,2 & 98,5 & 98,8 \\
Ens_Fundamental & $\mathbf{1 9 9 1}$ & 84,1 & 88,9 & 91,9 & 94,2 & 95,2 & 95,7 & 96,2 \\
(\%) & $\mathbf{2 0 0 0}$ & 76,0 & 83,5 & 87,0 & 89,8 & 91,6 & 92,7 & 94,3 \\
& $\mathbf{2 0 1 0}$ & 59,3 & 65,9 & 69,9 & 73,8 & 76,8 & 79,2 & 82,0
\end{tabular}

13 Tabelas expressando os indicadores para todas as mesorregióes do Nordeste podem ser obtidas via solicitação aos autores. 


\begin{tabular}{ccccccccc}
\hline Indicadores & Ano & Mínimo & $\mathbf{p 1 0}$ & $\mathbf{p 2 5}$ & $\mathbf{p 5 0}$ & $\mathbf{p 7 5}$ & $\mathbf{p 9 0}$ & Máximo \\
\hline & $\mathbf{1 9 8 0}$ & 40,1 & 52,6 & 54,2 & 59,3 & 63,1 & 65,2 & 69,9 \\
Tx. Analfabetismo & $\mathbf{1 9 9 1}$ & 26,8 & 41,1 & 46,2 & 50,8 & 54,4 & 57,2 & 59,8 \\
$\mathbf{( \% )}$ & $\mathbf{2 0 0 0}$ & 15,8 & 27,4 & 31,8 & 35,3 & 39,7 & 41,9 & 46,6 \\
& $\mathbf{2 0 1 0}$ & 11,9 & 20,7 & 24,1 & 26,0 & 29,8 & 32,6 & 35,6 \\
\hline
\end{tabular}

Fonte: Elaboração dos autores com base nos microdados do Censo.

Notas: $\mathrm{O}$ termo p10 indica o $10^{\circ}$ percentil, raciocínio similar para os demais casos.

A Tabela 5 contém a evolução das variáveis da dimensão infraestrutura do domicílio, baseada nos percentis das situaçôes presenciadas nas 42 mesorregiōes do Nordeste. Há forte evolução, com menores privaçóes, considerando as diferentes variáveis. Porém, as diferenças nas condições dos indicadores dos pobres entre essas mesorregiốes são muito maiores comparativamente à dimensão educaçấo. Por exemplo, em 2010, a proporçáo de pobres que não possuíam acesso à água canalizada proveniente da rede geral, poço ou nascente era de 15,9\% na região metropolitana de Fortaleza (melhor indicador), comparados aos 65,9\% presenciados no Norte Maranhense (pior indicador). As cinco melhores situaçóes ocorreram nas mesorregióes Metropolitana de Fortaleza, Metropolitana de Salvador, Metropolitana de Recife, Leste Potiguar e Mata Paraibana, enquanto as piores eram: Norte Maranhense, Sertão Alagoano, Leste Maranhense, Oeste Maranhense e Centro Maranhense.

A Tabela 6 apresenta a evolução das variáveis da dimensão posse de bens, baseada nos percentis das situaçóes presenciadas nas 42 mesorregióes do Nordeste. Avanços significativos também são notados com destaque para heterogeneidade existente entre as mesorregiôes. Nos casos da geladeira e televisão, as privaçóes tiveram fortes reduçóes na última década com foco nos valores dos percentis mais altos (mesorregióes com maiores privaçóes). Para telefonia, o ganho ocorreu também na década de 2000, mas com reduçóes mais fortes nos percentis mais baixos.

Tabela 5- Indicadores de privação na infraestrutura da habitação, distribuição em percentis com base nas 42 mesorregióes do Nordeste, 1980-2010

\begin{tabular}{lcccccccc}
\hline Indicadores & Ano & Mínimo & $\mathbf{p 1 0}$ & $\mathbf{p 2 5}$ & $\mathbf{p 5 0}$ & $\mathbf{p 7 5}$ & $\mathbf{p 9 0}$ & Máximo \\
\hline & $\mathbf{1 9 8 0}$ & 20,0 & 49,1 & 71,0 & 77,2 & 83,5 & 86,1 & 90,9 \\
Energia (\%) & $\mathbf{1 9 9 1}$ & 3,3 & 18,1 & 31,0 & 44,9 & 55,3 & 59,7 & 71,8 \\
& $\mathbf{2 0 0 0}$ & 0,9 & 5,1 & 12,2 & 18,4 & 32,9 & 42,4 & 51,6 \\
& $\mathbf{2 0 1 0}$ & 0,3 & 1,0 & 1,3 & 2,3 & 7,1 & 10,3 & 24,9 \\
& $\mathbf{1 9 8 0}$ & 20,6 & 44,6 & 56,6 & 72,8 & 82,2 & 84,0 & 92,2 \\
Sanitário (\%) & $\mathbf{1 9 9 1}$ & 17,4 & 27,9 & 40,5 & 58,5 & 65,6 & 73,5 & 81,8 \\
& $\mathbf{2 0 0 0}$ & 8,7 & 15,0 & 25,7 & 42,4 & 51,1 & 61,4 & 71,0 \\
& $\mathbf{2 0 1 0}$ & 1,9 & 4,6 & 7,9 & 17,0 & 26,6 & 33,3 & 44,0
\end{tabular}




\begin{tabular}{lcccccccc}
\hline Indicadores & Ano & Mínimo & $\mathbf{p 1 0}$ & $\mathbf{p 2 5}$ & $\mathbf{p 5 0}$ & $\mathbf{p 7 5}$ & $\mathbf{p 9 0}$ & Máximo \\
\hline \multirow{4}{*}{ Água (\%) } & $\mathbf{1 9 8 0}$ & 67,4 & 75,0 & 85,1 & 89,7 & 93,1 & 95,2 & 96,8 \\
& $\mathbf{1 9 9 1}$ & 43,2 & 56,0 & 65,5 & 75,0 & 83,0 & 87,1 & 90,8 \\
& $\mathbf{2 0 0 0}$ & 32,0 & 38,0 & 56,4 & 64,5 & 71,1 & 80,5 & 85,4 \\
& $\mathbf{2 0 1 0}$ & 15,9 & 25,9 & 36,7 & 43,1 & 53,1 & 58,4 & 65,9 \\
& $\mathbf{1 9 8 0}$ & 57,6 & 85,6 & 91,2 & 94,1 & 96,8 & 98,0 & 99,7 \\
Esgoto (\%) & $\mathbf{1 9 9 1}$ & 59,6 & 73,1 & 87,5 & 91,4 & 95,4 & 96,3 & 98,7 \\
& $\mathbf{2 0 0 0}$ & 46,2 & 67,7 & 73,5 & 81,8 & 88,6 & 90,6 & 94,0 \\
& $\mathbf{2 0 1 0}$ & 35,6 & 58,0 & 66,0 & 76,3 & 86,6 & 89,5 & 91,8 \\
& $\mathbf{1 9 8 0}$ & 66,1 & 67,5 & 69,7 & 74,0 & 77,5 & 81,2 & 84,2 \\
Densidade (\%) & $\mathbf{1 9 9 1}$ & 56,4 & 60,8 & 63,7 & 67,8 & 72,6 & 76,1 & 79,9 \\
& $\mathbf{2 0 0 0}$ & 49,9 & 55,4 & 58,5 & 61,8 & 67,1 & 68,3 & 70,9 \\
& $\mathbf{2 0 1 0}$ & 37,5 & 42,2 & 46,7 & 50,0 & 55,4 & 58,3 & 61,5 \\
\hline
\end{tabular}

Fonte: Elaboração dos autores com base nos microdados do Censo e auxílio do software Stata 15 .

Notas: $\mathrm{O}$ termo p10 indica o $10^{\circ}$ percentil, raciocínio similar para os demais casos.

Tabela 6- Indicadores de privaçáo na posse de bens dos pobres, distribuiçáo em percentis com base nas 42 mesorregióes do Nordeste, 1980-2010

\begin{tabular}{|c|c|c|c|c|c|c|c|c|}
\hline Indicadores & Ano & Mínimo & p10 & p25 & $\mathrm{p} 50$ & p75 & p90 & Máximo \\
\hline \multirow{4}{*}{ Geladeira (\%) } & 1980 & 64,9 & 81,1 & 88,0 & 91,5 & 94,1 & 94,9 & 96,1 \\
\hline & 1991 & 36,3 & 48,7 & 55,2 & 62,2 & 68,8 & 70,4 & 79,9 \\
\hline & 2000 & 22,9 & 38,3 & 50,0 & 61,5 & 66,3 & 70,9 & 74,2 \\
\hline & 2010 & 8,6 & 13,1 & 17,5 & 24,5 & 31,6 & 36,4 & 41,1 \\
\hline \multirow{4}{*}{ Televisáo (\%) } & 1980 & 48,6 & 73,6 & 84,3 & 90,5 & 93,0 & 95,0 & 99,3 \\
\hline & 1991 & 31,0 & 37,3 & 45,3 & 48,9 & 52,5 & 55,5 & 64,5 \\
\hline & 2000 & 12,6 & 17,8 & 23,9 & 32,5 & 45,5 & 53,9 & 64,2 \\
\hline & 2010 & 4,2 & 5,6 & 6,4 & 9,0 & 16,0 & 19,6 & 33,9 \\
\hline \multirow{4}{*}{ Telefone (\%) } & 1980 & 97,3 & 98,7 & 98,9 & 99,3 & 99,6 & 99,6 & 99,9 \\
\hline & 1991 & 96,8 & 98,1 & 98,9 & 99,2 & 99,4 & 99,6 & 99,8 \\
\hline & 2000 & 81,9 & 91,7 & 95,6 & 97,4 & 98,2 & 98,7 & 99,1 \\
\hline & 2010 & 14,4 & 21,0 & 29,0 & 36,6 & 48,0 & 58,0 & 66,3 \\
\hline
\end{tabular}

Fonte: Elaboração dos autores com base nos microdados do Censo e auxílio do software Stata 15.

Notas: O termo p10 indica o $10^{\circ}$ percentil, raciocínio similar para os demais casos.

A Tabela 7 segue o mesmo contexto das três tabelas anteriores, sendo que com base nos índices de privação das três dimensôes. E para melhor visualização das diferenças entre as mesorregiôes do Nordeste, a Figura 1 mostra esses índices com base no ano 2010. Os resultados indicam que ocorreram melhorias já discutidas nas tabelas anteriores, presenciadas de forma geral nas mesorregióes e nas três dimensóes. Sendo que os cinco maiores avanços 
(quedas em termos absolutos) ocorreram no: Noroeste Cearense, Extremo Oeste Baiano, Sertões Cearense, Norte Cearense e Oeste Maranhense (para dimensão educação); Sertão Sergipano, Borborema, Central Potiguar, Agreste Sergipano e Oeste Potiguar (infraestrutura do domicílio) e Oeste Potiguar, Agreste Potiguar, Central Potiguar, Jaguaribe e Sertão Paraibano (posse de bens).

Tabela 7- Indicadores de posse de bens dos pobres, distribuição em percentis com base nas 42 mesorregióes do Nordeste, 1980-2010

\begin{tabular}{lcccccccc}
\hline Indicadores & Ano & Mínimo & $\mathbf{p 1 0}$ & $\mathbf{p 2 5}$ & $\mathbf{p 5 0}$ & $\mathbf{p 7 5}$ & $\mathbf{p 9 0}$ & Máximo \\
\hline \multirow{4}{*}{ I. Educaçáo } & 1980 & 0,55 & 0,66 & 0,70 & 0,74 & 0,76 & 0,78 & 0,80 \\
& 1991 & 0,45 & 0,53 & 0,58 & 0,62 & 0,65 & 0,67 & 0,69 \\
& 2000 & 0,33 & 0,41 & 0,43 & 0,45 & 0,47 & 0,49 & 0,51 \\
& 2010 & 0,25 & 0,31 & 0,32 & 0,34 & 0,37 & 0,38 & 0,41 \\
I. Infra. & 1980 & 0,56 & 0,63 & 0,75 & 0,80 & 0,86 & 0,88 & 0,90 \\
Habitaçáo & 1991 & 0,42 & 0,47 & 0,60 & 0,68 & 0,73 & 0,77 & 0,81 \\
& 2000 & 0,33 & 0,39 & 0,46 & 0,53 & 0,61 & 0,67 & 0,69 \\
& 2010 & 0,22 & 0,30 & 0,33 & 0,38 & 0,43 & 0,50 & 0,52 \\
I. Posse de & 1980 & 0,71 & 0,85 & 0,91 & 0,94 & 0,95 & 0,97 & 0,98 \\
Bens & 2000 & 0,55 & 0,60 & 0,67 & 0,71 & 0,73 & 0,74 & 0,81 \\
& 2010 & 0,42 & 0,51 & 0,57 & 0,64 & 0,70 & 0,73 & 0,78 \\
& & 0,09 & 0,14 & 0,18 & 0,24 & 0,31 & 0,37 & 0,47 \\
\hline
\end{tabular}

Fonte: Elaboração dos autores com base nos microdados do Censo e auxílio do software Stata 15.

Notas: $\mathrm{O}$ termo p10 indica o $10^{\circ}$ percentil, raciocínio similar para os demais casos.

Em relação à distribuição (Figura 1), as piores situações para privação em educação estão relacionadas ao estado de Alagoas como um todo, ao agreste de Pernambuco, Sergipe (exceção da parte leste) e mesorregióes dos estados do Maranhão e Piauí (Norte Piauiense, Sudeste Piauiense, Centro Maranhense e Leste Maranhense). O estado do Ceará tem destaque com quatro mesorregióes pertencentes ao primeiro quartil, ou seja, com menores índices de privação na dimensão educação ${ }^{14}$, esse quartil é formado também por áreas que são compostas pelas capitais de boa parte dos estados (exceçóes da Paraíba e de Alagoas). Referente às dimensóes infraestrutura e posse de bens, pode ser notado que as mesorregióes da parte leste, onde se encontram a maior parte das capitais do Nordeste, possuem as menores privaçôes, enquanto as maiores privações ocorrem na região mais a oeste. O primeiro quartil dessa dimensão é formado pelo Sertão Alagoano, parte da Bahia,

14 O Ceará tem recebido destaque no campo educacional de crianças e adolescentes. Por exemplo, Rocha et al. (2018) mostram a existência de impactos positivos de políticas educacionais sobre os anos iniciais do Ensino Fundamental no município de Sobral. Os autores destacam que um fator importante dessas melhorias foi a gestão municipal de educação com foco na qualidade educacional (boa alfabetização, material didático, capacitaçáo de docentes, valorizaçáo dos profissionais, maior liberdade para diretores e sistemas de avaliaçáo). 
Maranhão e Piauí (adicionalmente Sertóes Cearense na dimensão posse de bens). Portanto, observa-se que, mesmo dentro da regiāo Nordeste, há fortes diferenças regionais.

Figura 1- Mapas dos índices de privação por dimensão, mesorregiōes do Nordeste, 2010

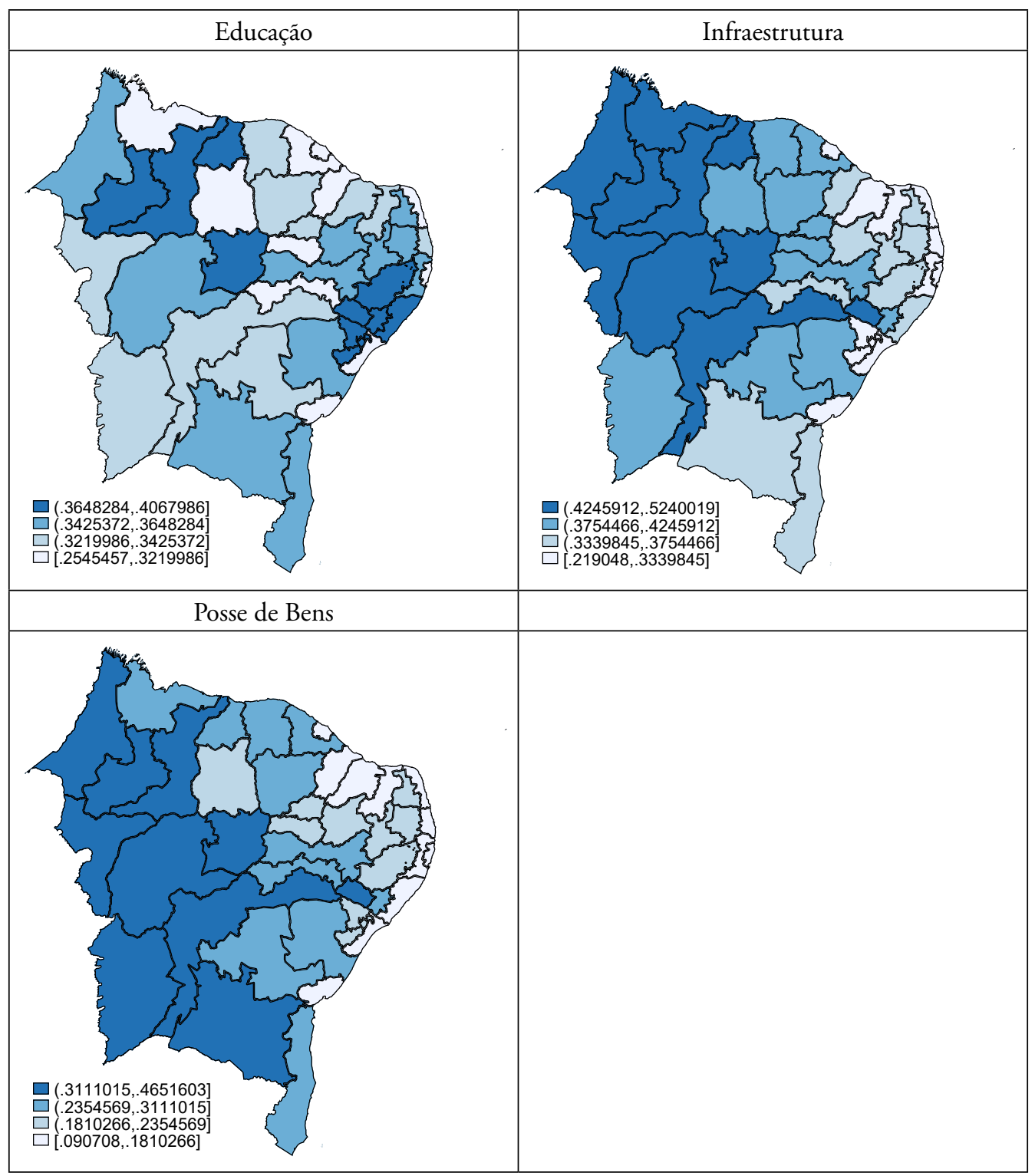

Fonte: Elaboração dos autores com base nos microdados do Censo e auxílio do software Stata 15.

A Figura 2 (apêndice) mostra os padrōes de autocorrelação espacial dos indicadores de privação dos pobres, através da abordagem de um "Local indicator of Spatial Associations (LISA)" com base nas mesorregiōes do Brasil no ano de 2010. O padrão Alto-alto (HighHigh), encontra-se nas regiôes Norte e Nordeste, indicando que as mesorregióes com altos 
índices de privação tendem a ser circunvizinhadas por lugares com esse mesmo padrão de indicadores (maiores privaçóes). Como em mapas anteriores, percebe-se que nas dimensóes infraestrutura do domicílio e posse de bens, esse padrão ocorre, principalmente, na parte mais a oeste da regiáo Nordeste (além de boa parte da macrorregiāo Norte). O padrão baixo-baixo (Low-Low, baixa privação em mesorregióes acompanhadas por suas vizinhas) se encontra em partes das regióes Sul e Sudeste, caracterizando claramente a espacialidade das privações concentradas nas duas primeiras macrorregióes supracitadas.

Figura A2- Mapas do LISA dos índices de privação por dimensão, mesorregiôes do Brasil, 2010

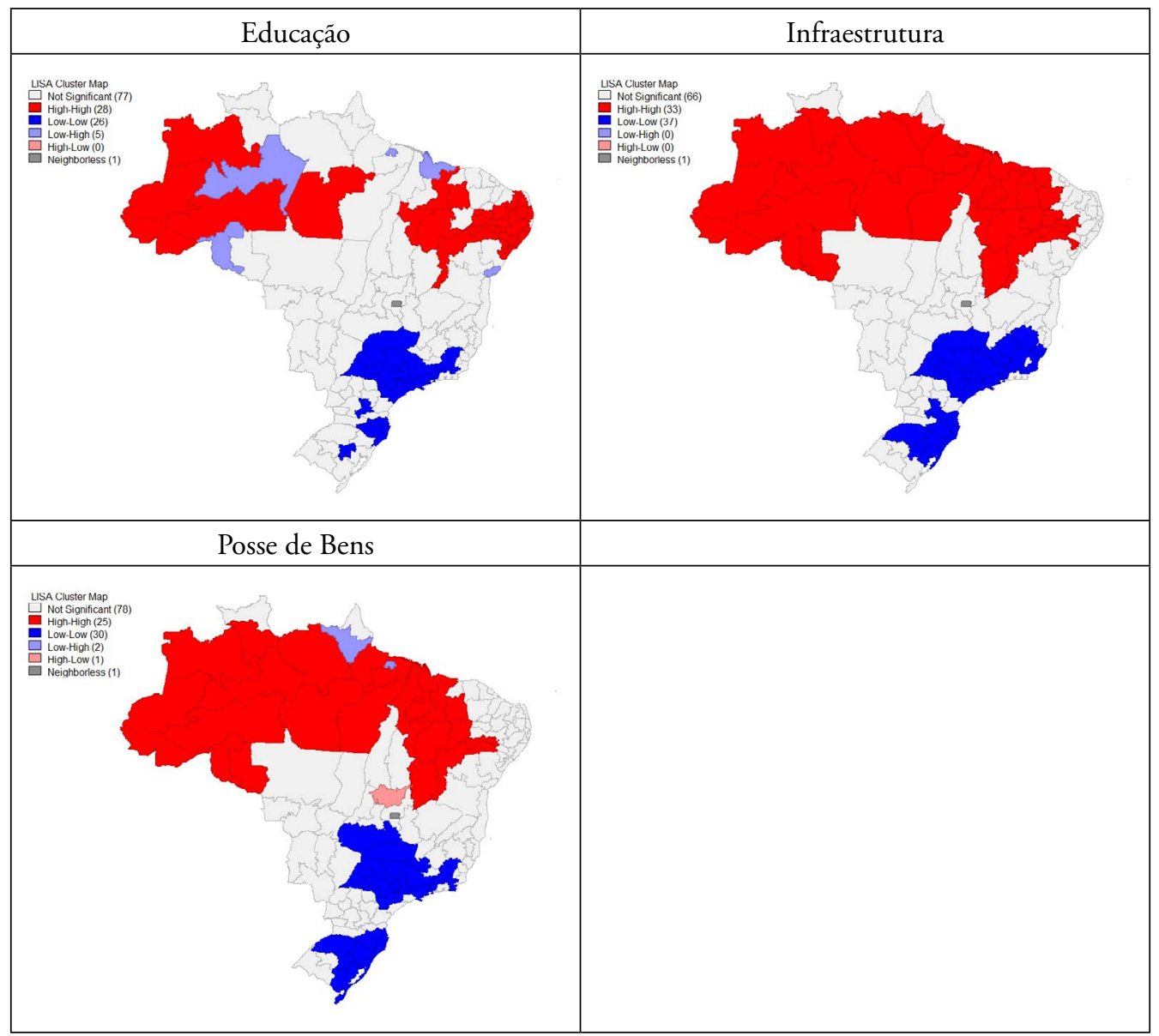

Fonte: Elaboração dos autores com base nos microdados do Censo e auxílio do software Stata 15 e Geoda.

\section{CONSIDERAÇÓES FINAIS}

Este trabalho buscou analisar o perfil dos pobres do Nordeste e de suas mesorregiōes com base no período de 1980 a 2010. Buscou-se, principalmente, analisar os índices de privação nas dimensōes educação, infraestrutura do domicílio e posse de bens, tentando 
contribuir de alguma forma na análise desagregada por mesorregiōes, considerando um período relativamente longo. Para tanto, os cálculos basearam-se nos microdados do Censo Demográfico.

Primeiramente, como forma descritiva, mostrou-se que a pobreza monetária foi reduzida, principalmente na última década de análise. No que se refere ao perfil e privaçóes da populaçáo pobre (classificada pela abordagem monetária, renda domiciliar per capita $\leq$ $\mathrm{R} \$ 140,00)$, melhorias importantes ocorreram ao longo do período, e, consequentemente, uma menor distância entre os indicadores de pobres e não pobres. Houve uma quase universalização na taxa de matrícula das crianças (7 a 14 anos) e no serviço de energia elétrica. Porém, apesar de todos os itens terem apresentado progresso, a questão do saneamento, a educação dos adultos e mesmo posse de bens básicos como geladeira se encontram em um patamar de privação bastante insatisfatório.

Ademais, a pobreza no Nordeste se mostra complexa, considerando que os índices dos não-pobres são semelhantes aos dos pobres do Sudeste. Essa conclusão precisa ser refletida com cautela, já que isso não indica dizer que as pessoas mais ricas, nessa primeira região, possuem um padrão de vida semelhante ao das mais pobres dessa última, já que muitos não pobres do Nordeste estão em situação de vulnerabilidade; além de que os índices aqui utilizados se referem apenas a bens e serviços básicos, como estar na escola, possuir geladeira, entre outros. Portanto, indica-se que não só os pobres da região Nordeste possuem privaçóes, apesar de serem os mais afetados.

A despeito das melhorias ocorrerem tanto na área rural como na urbana, as privaçóes nessa primeira área são bastante acentuadas e superiores. Na análise de mesorregióes, notouse que há diferenças nas privaçóes dos pobres dentro da própria região Nordeste, por exemplo, as carências nas dimensóes de infraestrutura do domicílio e posse de bens foram maiores na parte mais a oeste da região. A análise de correlação espacial mostrou que a regióes Norte e Nordeste possuem mesorregióes com privaçóes altas que têm esse padrão acompanhado pelas suas vizinhas. Nesse caso, políticas públicas precisam levar em consideração que os pobres classificados monetariamente possuem diferentes condiçóes socioeconômicas de acesso a bens e serviços básicos, com maior vulnerabilidade, principalmente no meio rural e em mesorregióes específicas. Assim, políticas públicas que visem melhorar o acesso dos mais pobres a bens e serviços devem apresentar fundamental importância, desde que levem em conta essa heterogeneidade existente.

Algumas das limitaçóes desse trabalho precisam ser destacadas. Uma maior equalização na educação das crianças não reflete diferenças de qualidade educacional, características de fundamental importância no bem-estar. $\mathrm{O}$ acesso a bens e serviços de saúde é uma dimensão importante, contudo, a indisponibilidade de dados não permitiu analisar esses indicadores; e mesmo as dimensóes analisadas são restritas aos dados disponíveis. Por fim, o censo possui a vantagem da desagregação, porém se encontra relativamente defasado, onde o contexto socioeconômico da população pode ter apresentado alteração significativa; a coleta e divulgação do próximo censo permitirão uma nova análise mais atualizada. 


\section{REFERÊNCIAS}

ANSELIN, L. Local Indicators of Spatial Association-LISA. Geographical Analysis, v. 27, n. 2, p. 93-115, 1 abr. 1995.

ARRETCHE, M. Trajetórias das desigualdades: como o Brasil mudou nos últimos cinquenta anos. In: ARRETCHE, M. (Ed.). Trajetórias das desigualdades: como o Brasil mudou nos últimos cinquenta anos. São Paulo: Unesp, 2015. p. 193-223.

BEZERRA, F. D.; KHAN, A. S.; ROCHA, L. A. Condicionantes da pobreza multidimensional nos municípios do Ceará pós-Constituição Federal de 1988. Revista Econômica do Nordeste, v. 46, n. 4, p. 155-176, 2015.

BOURGUIGNON, F.; CHAKRAVARTY, S. R. The Measurement of Multidimensional Poverty. The Journal of Economic Inequality, v. 1, n. 1, p. 25-49, 1 abr. 2003.

BUAINAIN, A. M.; DEDECCA, C. S.; NEDER, H. D. Características Regionais da Pobreza Rural no Brasil: Algumas Implicaçôes para Políticas Públicas. In: BUAINAIN, A. M.; DEDECCA, C. S.; NEDER, H. D. (Eds.). A nova cara da pobreza rural: desenvolvimento e a questáo regional. Brasília: IICA, 2013. v. 17p. 57-154.

CALDAS, R. DE M.; SAMPAIO, Y. DE S. B. Pobreza no nordeste brasileiro: uma análise multidimensional. Revista de Economia Contemporânea, v. 19, n. 1, p. 74-96, abr. 2015.

COSTA, M. A.; MARGUTI, B. O. Atlas da vulnerabilidade social nos municípios brasileiros. Brasília: IPEA, 2015.

FOSTER, J.; GREER, J.; THORBECKE, E. A Class of Decomposable Poverty Measures. Econometrica, v. 52, n. 3, p. 761-766, 1984.

GOLGHER, A. Multidimensional poverty in urban Brazil: income, assets and expenses. International Journal of Social Economics, v. 43, n. 1, p. 19-38, 2016.

GORI, A. Distribuição de rendimentos e qualidade de vida dos domicílios rurais brasileiros. In: BUAINAIN, A. M. [ET AL.] (Ed.). A Nova Cara da Pobreza Rural: desafios para as políticas públicas. Brasília: IICA, 2012. v. 16p. 335-366.

HOFFANN. R. Distribuiçáo de renda: medidas de desigualdade e pobreza. São Paulo: Edusp, 1998.

IPEA. Duas décadas de desigualdade e pobreza no Brasil medidas pela Pnad/IBGE: Comunicados do IPEA, n ${ }^{\circ}$ 159. Brasília: IPEA, 2013.

KAGEYAMA, A.; HOFFMANN, R. Pobreza no Brasil: uma perspectiva multidimensional. Economia e Sociedade, v. 15, n. 1, p. 79-112, 2006. 
LAVINAS, L.; COBO, B. Alcance e limite das políticas sociais para o combate à pobreza: desafios do mundo rural. In: BUAINAIN, A. M. [ET AL.] (Ed.). A Nova Cara da Pobreza Rural: desafios para as políticas públicas. Brasília: IICA, 2012. v. 16p. 367398.

MATTOS, E. J. DE; SANTOS, A. M. A. DOS. Pobreza rural na região Nordeste do Brasil: uma perspectiva além da renda. Economia e Sociedade, v. 38, n. 14, p. 8-22, 2017.

MENEZES FILHO, N.; KIRSCHBAUM, C. Educação e desigualdade no Brasil. In: ARRETCHE, M. (Ed.). Trajetórias das desigualdades: como o Brasil mudou nos últimos cinquenta anos. São Paulo: Unesp, 2015. p. 109-132.

NEDER, H. D.; BUAINAIN, A. M.; SILVA, G. J. C. A pobreza rural no Brasil. uma abordagem de mensuração multidimensional. In: BUAINAIN, A. M.; DEDECCA, C. S.; NEDER, H. D. (Eds.). . A nova cara da pobreza rural: desenvolvimento e a questáo regional. Brasília: IICA, 2013. v. 17p. 461-504.

PERO, V.; CRUZ, G. F. A queda da pobreza no Brasil: mudanças no perfil e nos determinantes na entrada do $2^{\circ}$ milênioAnais do $43^{\circ}$ Encontro Nacional de Economia. Anais... In: $43^{\circ}$ ENCONTRO NACIONAL DE ECONOMIA. Niterói: 2015

ROCHA, R. H.; MENEZES-FILHO, N.; KOMATSU, B. K. Avaliando o impacto das políticas de Sobral. Policy Paper no 35, Insper- Centro de Políticas Públicas. Brasília: IPEA, 2013.

ROCHA, S. Pobreza no Brasil: A Evoluçáo de Longo Prazo (1970-2011) XXV Fórum Nacional. Anais... In: XXV FÓRUM NACIONAL. Rio de Janeiro: 2013

SALVATO, M. A.; MATIAS, J. DE S.; BARROSO, M. DE V. Análise multidimensional da pobreza no Nordeste brasileiro. Revista Econômica do Nordeste, v. 48, n. 2, p. 25-44, 17 out. 2017.

SEN, A. K. Commodities and capabilities. Amsterdam: North Holland, 1985.

SEN, A. K. Desenvolvimento como liberdade. São Paulo: Companhia das Letras, 2000.

SEN, A. K. Desigualdade reexaminada. Rio de Janeiro: Record, 2001.

SERRA, A. S.; YALONETZKY, G. I.; BELIK, W. POBREZA MULTIDIMENSIONAL NO BRASIL, 2000/2010Anais do $45^{\circ}$ Encontro Nacional de Economia. Anais... In: 45 ${ }^{\circ}$ ENCONTRO NACIONAL DE ECONOMIA. Natal: 2017

SILVA, A. F. DA et al. Análise da pobreza multidimensional no Brasil no período de 2009 a 2015. Revista Econômica do Nordeste, v. 48, n. 2, p. 9-24, 17 out. 2017. 
SOARES, S. et al. Metodologias Para Estabelecer a Linha de Pobreza: Objetiva, Subjetivas, Relativas e Multidimensionais. Texto para Discussão TD-1381, IPEA, 2009.

SOARES, S. et al. Perfil da pobreza: Norte e Nordeste rurais: Policy Research Brief 50 . [s.l.] International Policy Centre for Inclusive Growth, 2016.

SOUZA, P. H. G. F.; OSORIO, R. G. O perfil da pobreza no Brasil e suas mudanças entre 2003 e 2011. In: CAMPELLO, T.; NERI, M. C. (Eds.). Programa Bolsa Família: uma década de inclusáo e cidadania. Brasília: Ipea, 2014. p. 139-155.

STRUMINSKI, C. E. C.; RAIHER, A. P. POBREZA E SEUS DETERMINANTES NOS MUNICÍPIOS BRASILEIROS: ABORDAGEM MONETÁRIA, DE PRIVAÇÓES E MULTIDIMENSIONAL. RDE - Revista de Desenvolvimento Econômico, v. 2, n. 37, 16 set. 2017. 